\title{
Estado y empresarios en el sector de la química básica en la Argentina: el proyecto de producción de álcalis sólidos*
}

GRACIELA PAMPIN**

Resumo: Este artigo analisa a relação entre empresários e Estado na instalação da ALPAT, produtora de carbonato de sódio. Depois de trinta anos, o Estado decidiu instalar a planta, na década de 1970; mas o projeto afundou num processo agitado: instável a partir de um ponto de vista institucional, crítico a partir de um ponto de vista econômico, e, ainda, com empresários que buscavam no Estado Nacional as fontes para seu lucro.

Abstract: This paper analyzes the relationship between entrepreneurs and the State in the installation of ALPAT, producer of soda solvay. After thirty years, the State decided to install the plant in the seventies; the project was submerged in a winding process: unstable from an institutional point of view, critical from the economic point of view, and with entrepreneurs who used the National State as source for their profits.

Palavras-chave: Química. Incentivo industrial. Empresas.

Key words: Chemistry. Industrial Promotion. Companies.

\section{Presentación}

La soda solvay (o carbonato de sodio) se constituyó desde fines del siglo XIX en un insumo imprescindible de diversas actividades fabriles. ${ }^{1}$ En ese sentido, la demanda de soda solvay presentaba

* Este trabajo es parte del proyecto UBACYT E-046 sobre el sector industrial en la Argentina.

** Facultad de Ciencias Económicas-UBA. E-mail: gpampin13@yahoo.com.ar

1 En 1861 Ernest Solvay creó un proceso basado en una serie de reacciones químicas, con el uso la sal común, la caliza y el amoníaco como materias primas, cuyo resultado es el carbonato de sodio y sus derivados. A pesar de sus efectos contaminantes, el $80 \%$ de la producción mundial de carbonato de sodio se realiza mediante este proceso.

Estudos Ibero-Americanos, PUCRS, v. XXXIV, n. 2, p. 130-149, dezembro 2008 
las mismas características que el de otros insumos básicos en la Argentina durante el proceso sustitutivo iniciado en los años treinta; en efecto, a medida que el proceso avanzaba y las divisas mermaban aparecían con mayor énfasis las preocupaciones en torno a la posibilidad de producirlos localmente. Así, la posibilidad de producir soda solvay se volvió una de las preocupaciones de los diferentes gobiernos durante, al menos, los últimos cincuenta años.

Este trabajo analiza en primer lugar el rol de los diferentes actores sociales, Estado-empresarios-técnicos, respecto de la posibilidad de producir la soda solvay en Argentina. En segundo lugar, presenta los años iniciales de la puesta en marcha e implementación del único proyecto aprobado para su fabricación local, el de Álcalis de la Patagonia SA. Finalmente, el trabajo concluye tratando de arrojar un poco de luz sobre la particular relación entre el Estado y los empresarios en un contexto de gran incertidumbre ambiental y se constituye en un caso paradigmático del fracaso de la consecución del desarrollo en la Argentina.

\section{Estudios, proyectos, indefiniciones}

En los años cuarenta, el Estado avanzó tímidamente hacia la consolidación del crecimiento industrial. Diversos organismos estatales fueron los encargados de estudiar, promover o inhibir el impulso a la producción de algunos bienes industriales.

Dos organismos se destacaron en el armazón político tendiente a reposicionar el sector industrial en un nuevo rol en la economía argentina: la Dirección General de Fabricaciones Militares (DGFM) y la Dirección Nacional de Industrias del Estado (DINIE).

La DGFM jerarquizó aquellas ramas del sector industrial consideradas estratégicas para la defensa nacional cuya promoción se realizaría a través de empresas mixtas que utilizaran materia prima nacional. A pesar de que la soda solvay no constituía estrictamente un insumo estratégico, desde 1946 se comenzaron a realizar estudios de factibilidad pero pocos años después resolvió descartar el proyecto.

Esta decisión se explicaría en parte por las restricciones presupuestarias impuestas por la nueva coyuntura económica pero también por las presiones de los grupos importadores de ese insumo. De hecho, el impulso a la producción de soda solvay por parte de la DGFM quedó trunco al mismo tiempo que un conflicto 
de intereses aparecía para permanecer a lo largo de todo el proceso. $^{2}$

En la década del cincuenta, las crisis del sector externo y la insuficiencia de divisas impulsaron nuevas búsquedas para sustituir importaciones. En esta década adquiere especial relevancia la participación de la DINIE que con el objetivo de formar un centro químico integrado en la Patagonia, retomó y profundizó los estudios precedentes. La DINIE resaltaba la necesidad de producir álcalis, imperioso para el desarrollo del sector químico, utilizando materias primas nacionales y en virtud del incremento de la demanda en el mercado interno. El Segundo Plan Quinquenal reforzó esta idea y puso en sus manos la ejecución de los proyectos a través de la Comisión Nacional de Álcalis.

El organismo elaboró estudios para lograr una producción mínima de 60.000 ton. de soda solvay (acorde al nivel de la demanda interna) con una inversión estimada en U\$S 9 millones; este esfuerzo de inversión se justificaba por el ahorro de divisas, equivalente al invertido, que generaría en menos de dos años.

El Estado avanzaba en definiciones más concretas que solo encontraban el silencio de los empresarios nacionales; en cambio, aparecieron en escena los empresarios extranjeros, estimulados por la nueva legislación sobre inversiones, cuyas ofertas se frustraron con el golpe militar que derrocó al gobierno peronista en 1955.

Así y todo, poco después la DINIE sugería la instalación de una sociedad mixta, planteaba la necesidad de resolver el problema del monopolio sobre la importación del producto, y reconocía la función del Estado como regulador, inversor, productor y garante de la promoción del sector.

No obstante estas definiciones, el proyecto no prosperó. Las presiones de los importadores y las dificultades burocráticas derivadas de la inestabilidad institucional, que ponía en discusión la existencia y el rol del organismo, fueron claves; el proceso político subsumía al económico y retrasaba las posibilidades de desarrollo.

Durante casi dos décadas el Estado intentó un camino no del todo lineal, primero tímido y luego más decidido aunque no sin contratiempos, orientado a profundizar el proceso de sustitutivo.

2 En ese entonces el principal importador era la empresa VASA (productora de vidrio plano) vinculada a la británica Pilkington principal distribuidora de soda solvay a nivel mundial. VASA consumía entre el 10 y el 15\% del producto importado (Rougier, 2007). 
Las indefiniciones para la producción de soda solvay tuvieron diversas causas pero en ese proceso el capital privado no solo no acompañó sino que, en algunos casos, obstaculizó su consecución.

Durante el gobierno de Arturo Frondizi la producción de insumos químicos industriales pareció tomar un nuevo impulso. En 1959 el decreto 16.970 preveía la instalación de una planta con capacidad para producir 200.000 ton. anuales de soda solvay; al parecer, el Estado estaba determinado a impulsar su producción sumando al capital privado.

La Compañía Industrial de Álcalis SA (CIDASA) presentó la propuesta de instalar una planta en San Antonio Oeste. La inversión estimada era de U\$S 25 millones para el complejo industrial y para 1965 la planta ya estaría en funcionamiento. Si bien se calculaba que el precio final de la soda solvay sería un $10 \%$ superior al producto importado, se estimaba que este precio se reduciría a medida que las inversiones fueran amortizadas y se enfatizaba en el ahorro de divisas que suponía su producción. Los empresarios privados parecían acompañar al Estado en la consolidación del proyecto industrial del gobierno.

El proyecto de CIDASA se enfrentó a un conjunto de avatares negativos. El gobierno desarrollista sucumbió frente a un nuevo golpe de estado. La política monetaria y fiscal del nuevo gobierno fue fuertemente restrictiva y la intensa devaluación que se aplicó castigó duramente al sector industrial. La crisis productiva y la caída del consumo se extendieron a lo largo de 1962 y 1963 paralizando todos los proyectos de inversión que estaban en marcha. La recesión dejó paso al crecimiento económico en 1964 y 1965 en el marco de un nuevo gobierno radical pero eso no impidió que el proyecto de soda solvay encontrara nuevos contratiempos. En particular pesaría fuertemente el diagnóstico negativo que la CEPAL, con influencia en la política económica del gobierno, tenía acerca de las posibilidades de fabricación de ese insumo en la Argentina.

Un informe realizado en 1966 por ese organismo sobre la industria química en América Latina destacaba la necesidad de desarrollar los álcalis sólidos y profundizar así el proceso de sustitución de importaciones atendiendo especialmente a los insumos necesarios para un sector industrial en constante crecimiento en gran parte de la región; justificaba así la instalación de dos plantas productoras de soda solvay en Latinoamérica en un corto plazo y con una capacidad de producción entre 160.000 y 240.000 toneladas anuales (CEPAL, 1966, p. 18). 
Para la CEPAL ninguno de los proyectos de la Argentina presentaba condiciones óptimas y destacaba que los altos costos de transporte tendrían una incidencia importante sobre el precio del producto terminado. Debemos considerar que de acuerdo al proyecto el precio final de la soda solvay (U\$S 71,5/ton.) sería competitivo con los precios internos del producto importado (U\$S 105/ton.) pero no con los precios internacionales (U\$S 34/ ton. CIF), por lo que difícilmente se podría exportar aunque esa alternativa no estaba en las perspectivas a corto plazo (CEPAL, 1966, p. 9).

Si la CEPAL desaconsejaba la instalación de una planta productora de álcalis en la Argentina, ello no significaba que el proyecto de CIDASA fuera inviable sino que priorizaba la radicación en otros países que reunieran ventajas comparativas en el marco de un proceso creciente y deseado de integración del comercio latinoamericano.

Pero desde la óptica nacional, el crecimiento del sector industrial, las dificultades para obtener divisas necesarias para la importación de insumos y un marco teórico que marcaba las necesidades de profundizar el proceso sustitutivo ponían en un segundo plano las consideraciones de la integración latinoamericana y priorizaba las necesidades locales. El proyecto debía avanzar de todos modos; los datos objetivos eran evidentes y mostraban la necesidad de producir localmente ese insumo clave para el sector industrial. Argentina dependía de la importación de soda solvay, la cual había crecido desde 1953 y se preveía un crecimiento aún mayor para los próximos diez años.

A mediados de los años sesenta se profundizaron los debates acerca de cuál sería la mejor estrategia de desarrollo en nuestro país. El proceso sustitutivo había mostrado límites concretos y, en la concepción de la época, era el momento adecuado para su profundización. Los intelectuales destacaban ciertos problemas estructurales de la industria local que debían ser solucionados: a medida que crecía, el sector manufacturero necesitaba bienes de capital e insumos más complejos y diversificados; la producción a escala se veía dificultada con un mercado interno reducido, peor aún si no se consideraba la posibilidad de exportar; y la alta protección no había logrado una eficiencia industrial como la de los países desarrollados.

Los analistas coincidían en la necesidad de impulsar "un proceso de especialización en un esquema abierto que permitiera 
por vía de la exportación industrial generar un plus de recursos externos indispensables para mantener la expansión de las importaciones y el crecimiento industrial" (Rougier, 2004, p. 65). Entre ellos, Aldo Ferrer proponía la creación de grandes plantas que permitiesen operar con economías de escala para abastecer al mercado local y a su vez tuviesen capacidad exportadora, teniendo en cuenta los recursos nacionales y una importante presencia del Estado.

El Estado recogió estas ideas y estimuló la inversión nacional, en regiones alejadas a la Capital y orientada hacia la producción de bienes o ramas estratégicos; aunque no siempre fueron acompañados por el sector privado (Schvarzer, 1996, p. 272 y ss.).

Por su parte los empresarios mostraban divergencias, algunos bregaban por profundizar la sustitución de importaciones de bienes químicos otros sólo se quedaban en declamaciones. Una política económica errática sin una orientación del todo clara generaba perspectivas difusas entre los empresarios; la inestabilidad de la rama química generaba serios inconvenientes ya que producía insumos muy importantes del sector industrial y sus productos eran de muy difícil colocación en el mercado externo, por lo tanto ante la caída de demanda en el mercado local las exportaciones no constituían una alternativa como ocurría con otros bienes.

Los empresarios del sector reconocían en la soda solvay un producto fundamental de la industria aun cuando ninguno avanzaba en la posibilidad de fabricarlo a nivel nacional ya que era considerada antieconómica y en peligro de ser desplazada por la aparición de bienes sustitutivos. Arturo Edbrooke, presidente de Duperial, señalaba que "el factor más importante para instalar una industria de soda solvay es contar con sal y piedra caliza muy accesibles, si se dan esas condiciones es posible elaborarla a bajo costo. No se sabe si esas condiciones están dadas en la Argentina (...) todo tiene que ser muy fácil y muy barato; de lo contrario, obviamente, los consumidores no tendrán interés en un producto nacional si es más caro que el importado". ${ }^{3}$

Recordemos que, según las estimaciones, la producción de soda solvay en Argentina si bien no podría competir en el mercado internacional su precio en el mercado interno sería menor que el

3 Competencia (1969), p. 22. 
del producto importado. Difícilmente este empresario desconociera los estudios y proyectos que aquí se han detallado; "muy fácil y muy barato" resume sus verdaderas inquietudes que podrían ser traducidas en inversiones seguras y con poco riesgo, o la declaración era parte de las presiones sobre el Estado para obtener mayores beneficios.

Al parecer, pudo más la declamación de los intelectuales y las necesidades impuestas por el desarrollo económico que la desidia que manifestaba el paso cansino de los empresarios. Las reticencias de la iniciativa privada, la "presión intelectual" que actuaba como sustento teórico y las necesidades impuestas por el desarrollo económico llevaron a que el Estado avanzara de manera más decidida hacia la producción de soda solvay en Argentina.

\section{La marcha del proyecto}

En 1969 se creó el "Fondo de Contribución para el Desarrollo del Carbonato de Sodio", con recursos provenientes de una contribución especial sobre las importaciones de soda solvay y administrados por el BIRA.

El gobierno llamó a licitación para promover la instalación de una planta con apoyo estatal, en donde se preveía capitalizar la empresa pero no intervenir en su administración; de esta forma se intentaba incentivar a los empresarios nacionales a incursionar en el sector. ${ }^{4}$

En 1970 el primer concurso internacional se declaró desierto. En una segunda licitación se presentaron Ferrostaal (Alemania), ALPAT (de capitales locales con participación de CIDASA) y Tata Chemicals (India). La mejor oferta provino de ALPAT, pero el Estado exigió la participación de las otras dos. Aparentemente, se verían cristalizados los resultados de los debates de la década previa y de tantos estudios y proyectos; las ideas de Ferrer parecían ponerse en marcha.

ALPAT y el Estado celebraron un contrato que tendría un presupuesto total de inversión de U\$S 36,8 millones. El acuerdo estableció la localización de la planta en San Antonio Oeste, Río Negro, en 130 has. cedidas por el gobierno provincial; una capacidad mínima de producción de 200.000 ton. por año y garantía

4 PEN, Decreto 8.566, 31 de diciembre de 1969. 
de calidad internacional. A mediados de 1975 la planta debía estar funcionando en, al menos, un $80 \% .^{5}$

ALPAT debía utilizar materias primas nacionales y realizar las obras de infraestructura necesarias para la colocación del producto en los mercados; su producción se destinaría al mercado nacional y el remanente a la exportación. Por su parte, el Estado se comprometía a garantizar que el producto importado no compitiese con el nacional y establecía una serie de beneficios impositivos para la firma. Este conjunto de medidas suponía el impulso al sector y la garantía de la implementación del proyecto en el corto plazo. ${ }^{6}$

En la conformación del capital accionario de ALPAT, CIDASA debía mantener el $60 \%$, por lo menos, del paquete accionario por considerarse una firma local. El contrato preveía que si la empresa incumplía los tiempos estipulados para la puesta en marcha del proyecto caducarían los derechos que le habían sido otorgados y los accionistas perdían el derecho a integrar las acciones que pasaba a favor del Estado.

A mediados de 1973 se comenzaron las tareas para construir la planta. Al asumir el gobierno constitucional de Juan Perón, se paralizaron las obras y se comenzó la revisión del contrato acorde a las nuevas orientaciones de la política económica. El gobierno propuso a los directivos de ALPAT una mayor participación de capital nacional y estatal en la empresa. La propuesta fue aceptada. Tata Chemicals se retiró y su aporte de capital fue sustituido por el gobierno de la provincia de Río Negro, el 90\% del capital accionario de ALPAT quedó en manos nacionales. ${ }^{7}$ Así se adecuaba el proyecto a la ley 20.557 de 1973 que establecía que una sociedad local, para recibir calificación de empresa de capital nacional no debía tener más del 20\% de capital extranjero.

A partir de entonces, el proyecto pareció tomar mayor impulso. La decisión del Estado de concretar el proyecto alentó las expectativas de los directivos de la empresa pero la inestabilidad política y económica de la Argentina profundizada luego de la

5 Ministerio de Industria y Minería, Contrato ALPAT, 1973. El Estado estipuló que la firma, emitiría acciones preferidas, que tomaría el Banco Nacional de Desarrollo (BND), con un $8 \%$ de interés anual, las que deberían ser rescatadas en un plazo no mayor de diez años (a partir de la puesta en marcha) por la Sociedad que explotara la planta. Luego, el BND confirió avales por U\$S 13,1 millones y créditos por U\$S 8,1 millones. Para un análisis del accionar del BND, véase Rougier (2004).

6 La ley 11.682 declaraba de interés nacional la producción de carbonato de sodio.

7 ALPAT, LAD 1, acta n. 10, 30 de octubre de 1973. 
muerte de Perón en julio de 1974 complicaría su prosecución. Con la caída del ministro de economía José Gelbard el proyecto pareció entrar en un compás de espera.

Ese año, las importaciones de soda solvay no llegaron a cubrir la demanda de la industria del vidrio por lo que las necesidades de producir ese insumo localmente se volvieron más acuciantes. Además se produjo un fuerte incremento de los precios de ese producto como consecuencia de los profundos cambios que se abrieron en la economía mundial a partir de la "crisis del petróleo".

Estado y empresarios observaban con preocupación el impacto que había generado el incremento de costos. Estos últimos afirmaban que "el problema global de abastecimiento que padece nuestra economía se vio agigantado durante 1974 por la falta de soda solvay (...) la historia de los proyectos fallidos de instalación de una planta en el país es, tal vez, una de las más ricas de la mitología del subdesarrollo"; y resaltaban que "la presencia de grandes proyectos oficiales inhibe la potencialidad inversora del sector privado. Pero, nunca se terminan de concretar". 8

Recordemos que unos años antes un empresario del sector no creía conveniente invertir en producir soda solvay por considerarla antieconómica; luego los empresarios de ALPAT estaban a favor de la participación estatal en el proyecto; ahora, otros criticaban al Estado por sus indefiniciones y la demora del proyecto, pero al mismo tiempo lo cuestionaban en su rol empresarial y como inhibidor de la acción privada (que nunca habían tomado la iniciativa).

En enero de 1975 el ministro de economía Alfredo Gómez Morales realizó modificaciones en el contrato tendientes a resguardar inversiones del Estado. Estas modificaciones nunca fueron firmadas por el ministro y ALPAT no pudo cumplir con las cláusulas financieras cuyas obligaciones estaban a cargo del BND ya que éste no recibía las instrucciones, estipuladas en el nuevo contrato no firmado, del Poder Ejecutivo. Esto reflejaba la situación política por la que atravesaba la Argentina en ese tiempo. El propio ministro no era atendido por la Presidenta de la Nación, Isabel Perón, como parte de un vacío político que precipitó finalmente su renuncia. Los conflictos al interior del gobierno atravesaban a la empresa; los empresarios veían al Estado como el principal obstáculo para la concreción de su dilatado proyecto; denunciaban

8 Competencia 1975, p. 65-66. 
que "debido a la culpa inexcusable de las autoridades públicas, se vea demorada la actividad de una industria básica (...) con un precio de plaza en continuo aumento, que se ha decuplicado desde la época que se abriera la licitación (...) no se alcanza a comprender cuál es el beneficio que reporta a la República una dilación burocrática que ya ha alcanzado límites inaceptables", ${ }^{9}$ y solicitaban al Ministerio que acelerase la resolución definitiva acerca de la estructura de la empresa. La situación política y económica en ese momento era explosiva. Las medidas económicas conocidas como "rodrigazo" impulsadas por el nuevo ministro de economía Celestino Rodrigo, en junio de 1975, provocaron numerosas reacciones sociales y una profunda incertidumbre económica.

Los empresarios de ALPAT criticaban las indefiniciones del gobierno y subrayaban que ellas solo beneficiaban "a los intereses ligados a la importación de soda solvay y acrecientan nuestra dependencia con el exterior". ${ }^{10}$

En diciembre de ese mismo año, Antonio Cafiero, nuevo ministro de economía reafirmó la decisión de continuar con el proyecto pero ahora con el Estado como accionista mayoritario; idea que entroncaba con el reposicionamiento en el gobierno de la “ortodoxia" peronista. Así, en enero de 1976, el Estado pasó a tener el 51\% del capital accionario.

En el ínterin las obras se habían paralizado nuevamente, y en función de las variaciones sufridas en los precios era necesario redefinir el nivel de inversiones. Paralelamente ALPAT recibía el primer embarque de equipos y solicitaba al Estado que acelerara los tiempos, fundamentalmente aquellos relacionados con el aporte del capital. Los constantes reclamos de la empresa ante el Poder Ejecutivo generaron que en marzo de 1976 la Secretaría de Desarrollo Industrial elaborara un nuevo contrato, cuyas negociaciones se vieron interrumpidas abruptamente por un nuevo golpe militar. La concreción del proyecto no podía escindirse del complejo proceso político-económico de los primeros setenta.

En suma, el proyecto ALPAT había comenzado en los mejores años de la industria argentina pero rápidamente la evolución política pareció devorarse al proceso económico. La llegada del peronismo al poder, el gran abanico ideológico que lo conformaba y la muerte de Perón, generaron disputas al interior del peronismo 
y del gobierno que no pudieron deslindarse de la dinámica de la empresa. Los sucesivos cambios de conducción económica y de orientación respecto al proyecto lograron que ALPAT quedara entrampada en estos avatares políticos, que demoraron y entorpecieron su ejecución.

En marzo de 1976 ocurrió el último y más feroz golpe de estado de la Argentina. El ministro de economía, José Martínez de Hoz, impuso cambios en la política económica que generaron modificaciones estructurales y afectaron específicamente al sector industrial. Sin embargo, "no expresó una posición clara frente a la industria en una primer etapa, tanto por sus propias indefiniciones como por el carácter de la alianza político-social en la que se sustentaba. Ese contexto explica que dejara seguir los proyectos fabriles promocionados en el período anterior, firmando los decretos y resoluciones pendientes en el resto de ese año" (Schvarzer, 1996, p. 294).

ALPAT era un caso pendiente. El gobierno constitucional había desatendido este proyecto en sus últimos meses de gestión y con el gobierno de facto, los empresarios se reacomodaban y declaraban que "durante el ejercicio 1975-1976 el país asistió a una de las más importantes convulsiones socioeconómicas y políticas de su historia contemporánea (que) llevaron a la Nación al borde de un colapso político-institucional que pudo ser evitado por la intervención militar del 24 de marzo". Pero, para los empresarios, la dictadura militar no cumplía sólo con la decorosa misión de salvar a la Nación sino también a la empresa ya que "el Gobierno Nacional (...) comenzó a realizar actos positivos para facilitar la marcha del proceso" teniendo en cuenta que "el proyecto ALPAT sufrió durante este período [el gobierno peronista] las consecuencias de la situación imperante en el país [que] impidieron un tratamiento eficaz de nuestro contrato a nivel oficial". ${ }^{11}$

Los directivos de la empresa reclamaron al nuevo gobierno un tratamiento urgente; éste comenzó a destrabar el proyecto. El gobierno solicitó a ALPAT una nueva propuesta para modificar el contrato con el Estado en donde prevalecieran las inversiones privadas; por su parte, los empresarios afirmaban entusiastas que esta reformulación permitiría concluir las obras. ${ }^{12}$

11 ALPAT; $M y B, 1976$.

12 En principio aprobó el ingreso de bienes de capital provenientes de Francia y Alemania, realizó un aporte de capital de U\$S 121.500 y prorrogó los pagarés avalados al Dresdner Bank de Alemania Federal. ALPAT; MyB, 1976. 
Paralelamente, el BND dispuso realizar un estudio sobre el caso ALPAT debido a que "el tratamiento dispensado ha respondido a decisiones adoptadas a nivel Directorio en las que han gravitado objetivos políticos y actuaciones producidas a niveles superiores de Gobierno". El estudio dejaba constancia de que el BND nunca había evaluado el proyecto; destacaba que CIDASA había cometido serias irregularidades; y aclaraba, con un tono inusualmente duro en ese organismo, que "de ser ciertas las irregularidades presumidas (...) podrían haberse cometido hechos contemplados en el Código Penal (...). El engaño, de haberse producido, no solo afecta al Banco sino al Estado Nacional". Adicionalmente, concluía que el proyecto sufría una serie de "carencias e indefiniciones" que lo llevaron al BND a "emitir el 2/11/77 opinión desfavorable para la concesión de créditos y avales a ALPAT SA. Pero el Directorio al considerar (...) la irrevocable decisión del Poder Ejecutivo Nacional de instalar la planta productora de carbonato de sodio y la magnitud y naturaleza de los compromisos ya asumidos por la Institución resolvió el 3/11/77 hacer saber a la titular la disposición del Banco para otorgar avales hasta U\$S 11.846.000 y créditos por \$ 3.117.340.000". ${ }^{13}$

Este era parte del diagnóstico negativo que si bien obedecía a cuestiones políticas e ideológicas también mostraban las deficiencias de funcionamiento de esa institución y mostraba las tensiones entre el Directorio del BND y el cuerpo técnico que se deslindaba de las cuestiones políticas.

Inicialmente el equipo económico se limitó a administrar algunos grandes proyectos de inversión industrial bajo el régimen de promoción ensayado por el gobierno peronista pero ello no impidió que lentamente el Estado se retirara del paquete accionario de la sociedad, proceso que daba un lugar más destacado al capital privado, nacional y extranjero.

En efecto, a fines de 1976 se aprobó el nuevo contrato entre el Estado y ALPAT. Los costos del proyecto se estimaron en U\$S 91.5 millones, y el capital social se fijó en U\$S 30,5, de los cuales el 40\%

13 BND, Informe reservado, 1978. "El Estado habría pactado y el Banco otorgado aval por U\$S 13.100 .000 y crédito por U\$S 8.100.00 asumiendo la existencia de un aporte real de capital por U\$S 5.000.000 por parte del grupo fundador, en su lugar solo habría existido una financiación del proveedor que se cancelaría a través de los pagos que la sociedad emisora de las acciones debía efectuar a CIDASA por suministro de piedra caliza. Desestimada la integración de U\$S 5.000.000 el capital realizado de ALPAT SA a la fecha a la formalización de las operaciones otorgadas por el Banco por U\$S 21.200.000 era solo de \$ 168.000". 
serían con aportes del Estado; la participación estatal había disminuido aunque los aportes se elevaban de U\$S 4 millones a U\$S 12 millones y se aseguraba una mayor participación del capital extranjero. Así, tempranamente se reflejaba en ALPAT el estímulo para estas inversiones al no tener un tratamiento discriminatorio con respecto al capital nacional como se reglamentará luego, con la ley 21.608 de promoción industrial.

Con ese capital social aún restaban U\$S 61 millones para financiar el proyecto; de ellos U\$S 23 pondría el BND a través de créditos para gastos locales, por su parte ALPAT se comprometía a obtener U\$S 38 millones de financiamiento externo. Por un lado, el Estado disminuía su participación en el capital social de la firma y promovía una mayor participación extranjera; por el otro, el proyecto no podía prescindir de su participación. Estas ambigüedades generaban en los empresarios la expectativa de obtener cada vez más financiamiento del Estado a la vez que conseguían beneficios tributarios sumamente ventajosos y protección arancelaria durante ocho años desde la puesta en marcha de la planta.

Las obras deberían estar terminadas a los veintiséis meses y la empresa se comprometía a informar cualquier demora en el cumplimiento. Además, si la Secretaría estimaba que el proyecto no avanzaba al ritmo estipulado o había sido abandonado ALPAT quedaría sujeta a una serie de sanciones y a ser excluida de los generosos créditos y avales otorgados por el Estado. ${ }^{14}$

Al parecer, los mecanismos de control estatal estaban previstos; sin embargo no estaba claro cómo se harían efectivos. En principio, el BND a través de sus técnicos elevaban los informes, luego los directivos decidían no en base a esos informes sino en función de las directivas de la Secretaría de Industria, la que a su vez respondía a los lineamientos del Ministerio de Economía, cuya política no era claramente unívoca respecto al sector industrial en su conjunto.

Con esas ambigüedades el Estado se retiraba, aseguraba una mayor participación de capital privado, otorgando créditos $\mathrm{y}$ avales; con ello generaba una nueva fuente de negocios alternativa para el sector privado. En efecto, a partir del contrato, la importación de carbonato de sodio estaba sujeta a un cupo anual de 180.000 toneladas, de las cuales 100.000 se adjudicaban a ALPAT; así, la empresa obtenía un negocio seguro con la comercialización de más del 50\% del producto importado.

14 Ministerio de Economía, Contrato de promoción industrial Ley n. 20.560. 
En el intento de poner freno a las demandas empresarias y de garantizar los límites para la participación estatal, se convino que ALPAT no podía requerir del Estado un aporte mayor al capital existente en el Fondo de Contribución. ${ }^{15}$

Si bien ALPAT reconocía que aún no había comenzado con las obras de infraestructura planteaba la necesidad de ampliar el capital social debido al problema inflacionario, tanto nacional como internacional. Por otra parte, ante el incumplimiento de los compromisos por parte del BND, a mediados de 1978, le envió un informe con un cálculo detallado de la importación anual de soda solvay estimando el incremento del Fondo de Contribución en alrededor de US\$ 3 millones. ${ }^{16}$ Si ALPAT no conseguía capitales frescos porque el Estado no le permitía incrementar el capital social, se los reclamaba a través de una herramienta de financiamiento que el mismo Estado le había dado pero en base a estimaciones propias.

En definitiva, hasta fines de 1978 la empresa había realizado estudios, importado algunas maquinarias que descansaban y comenzaban a envejecer en un galpón, conformado una deuda con el BND entre créditos y avales por U\$S 20,24 millones (con un pasivo total de U\$S 28 millones) pero aún no había comenzado la construcción de las obras. De los veintiséis meses calculados para la puesta en marcha de la planta desde la firma del último contrato ya habían pasado veinte. Ese retraso no impidió al presidente de ALPAT presionar a las autoridades nacionales para que de manera urgente se hicieran efectivos los aportes estatales. ${ }^{17}$

La actitud cansina del Estado respecto a los requerimientos de la empresa contrastaba con la de los empresarios, sumamente dinámica y emprendedora para reclamar beneficios ante el Estado. La falta de respuesta estatal era en parte consecuencia de que ALPAT era un proyecto heredado, en parte porque los empresarios no habían cumplido con los plazos previstos, pero también en parte por los desacuerdos al interior del mismo gobierno.

Las tensiones comenzaban a cristalizarse no solo entre Estado y empresarios sino al interior del mismo Estado que se trasladaban

15 Ministerio de Economía, Secretaría de Estado de Desarrollo Industrial, Convenio Complementario del Contrato celebrado entre ALPAT SA y el Estado Nacional, 27 de julio de 1977.

16 Memorando, A: Cont. José M. Mata, De: Sr. Cristian Gautier; Asunto; “Cálculo incremento del Fondo de Contribución del Carbonato de Sodio para el año 1978", 27 de septiembre de 1978.

17 Acta de Directorio, n. 133, 22 de noviembre de 1978. 
al interior de la empresa. A partir de este momento las principales desavenencias en la Asambleas de ALPAT se produjeron entre el representante del BND (Brigadier Rubén Bonoris) y el representante de la Secretaría de Industria (Dr. Luis García Conde). Además, una serie de cambios de funcionarios en el gobierno reflejaban las tensiones en su interior. En estas circunstancias, el BND se veía obligado a legitimar su accionar frente a la opinión pública. $^{18}$

Las tensiones y las consecuentes indefiniciones coadyuvaban a las demoras del proyecto que derivaban en un incremento de los costos; en diciembre de 1978 ALPAT planteó la necesidad de incrementar el capital social "para seguir atendiendo las erogaciones que demanda el desenvolvimiento de la empre$\mathrm{sa}^{\prime \prime} .{ }^{19}$

El Estado retrocedía y al parecer los empresarios habían decidido llevar el proyecto adelante. Al año siguiente, CIDASA y el Grupo Fundador ofrecieron incrementar su participación en el capital de la sociedad con aportes genuinos lo cual significaba una disminución del aporte del capital estatal. En el nuevo contrato la participación estatal quedó reducida al 30\%. ${ }^{20}$

Sin embargo, para 1979 la empresa estimó que el costo total de inversión para poner en funcionamiento la planta era de aproximadamente U\$S 236 millones (tres años antes se habían calculado en U\$S 95 millones). De esa cantidad requerida sólo se había invertido alrededor del 35\%, la mayoría a través de créditos con garantía estatal u otorgados directamente por el Estado.

A partir de los nuevos cálculos, la inversión a realizar entre 1978 y 1979 se había incrementado en un 43\%; el BND debía

18 El Brigadier Bonoris exponía su "convicción de que la empresa debía adoptar una posición definida frente a algunos juicios (...) en el sentido de que para la fabricación de la soda solvay no existe proyecto, con el agravante de que se pretendería condicionar la resolución final para materializar los propósitos de la sociedad, a la presentación del llamado proyecto definitivo (...) la empresa no debe caer en la trampa de presentar un nuevo proyecto o de demostrar nuevamente la factibilidad del emprendimiento iniciado (...) mociona el Sr. Director Bonoris, para que el Directorio asuma y sostenga categóricamente ante terceros que el presentado el julio de 1976 es el proyecto de esta empresa, el cual fue aprobado oficialmente y cuyos lineamientos rigen (...) la marcha de ALPAT". Acta de Directorio, n. 133, 22 de noviembre de 1978.

19 ALPAT; Asamblea General Ordinaria, 18 de diciembre de 1978.

20 Ministerio de Economía; Decreto 297/79 modificatorio del Contrato Estado Nacional - ALPAT. Entre otras modificaciones se destacaba la imposición de sanciones monetarias por las demoras en la ejecución del proyecto. 
financiar el 70\% de los gastos locales y avalar el 80\% de las compras de equipo externo, además de refinanciar la deuda a largo plazo ya vencida o a vencer. En consecuencia, los requerimientos financieros sumaban U\$S 200.166.000 más U\$S 30 millones correspondientes a pasivos preexistentes por deudas. El total de estos serían refinanciados con capital propio mientras que el BND aportaría créditos y avales por U\$S 165.739.000 que representaban el 72\% del total.

ALPAT pretendía elevar el capital social de la firma con mayores aportes estatales. Los empresarios propusieron una nueva emisión de acciones para incrementar el capital en U\$S 1,75 millones (U\$S 700 mil debía suscribir el Estado). En principio el Ministerio de Economía se negó a realizar estos aportes que eran en realidad los que debían haber hecho los privados un año antes. ${ }^{21}$ Más tarde, y a pesar de los incumplimientos del sector privado el Estado continuó contribuyendo con la empresa; en 1980 el BND aportó U\$S 7,3 millones elevando la participación estatal a un total de U\$S 8 millones sobre un total comprometido de U\$S 9,15. ${ }^{22}$ Esos aportes no parecían suficientes para los empresarios que pedían más financiamiento para efectivizar el proyecto. El Estado resistía los embates de los accionistas privados y las tensiones se visualizaban cada vez con mayor intensidad.

Hacia los años ochenta el pasivo total de ALPAT ascendía U\$S 58,6 millones, de modo que duplicaba en dólares el valor del año anterior. Sin embargo en cuanto a la concreción del proyecto los empresarios habían continuado los estudios e incorporado equipos; los informes decían que se avanzaba en la organización de una estructura moderna para la empresa, aunque no se habían realizado siquiera los cimientos de la planta.

En 1981 un decreto del PEN actualizaba el costo del proyecto en U\$S 300 millones y se proponía privatizar el capital accionario en manos del Estado, una medida que también se llevaba a cabo con los paquetes accionarios de firmas privadas controladas directamente por organismos públicos. ${ }^{23}$ En este proceso suma-

21 ALPAT; Asamblea General Ordinaria, n. 31, 29 de agosto de 1979; Asamblea Especial Unánime de accionistas Clase B, Acta n. 32, 29 de agosto de 1979; y Asamblea General Ordinaria n. 33, 29 de agosto de 1979.

22 ALPAT; Asamblea General Ordinaria, n. 36.

23 PEN, Decreto 697/1981. El decreto fue publicado por el Boletín Oficial los primeros días de abril de 1981, pero seguramente era uno de los últimos firmados por Martínez de Hoz, que dejó el ministerio el 31 de marzo. 
mente engorroso, ALPAT cambió su composición social aunque continuaron participando los antiguos empresarios.

El Estado había colaborado ostensiblemente para incrementar la deuda de la empresa pero difícilmente accionó los mecanismos de control necesarios para que esos capitales inexorablemente resultaran en una inversión productiva. Como afirmó un alto funcionario de la dictadura, "en San Antonio, a la soda Solvay la llaman ahora Landriscina. ¿Sabe por qué? Porque es puro cuento". ${ }^{24}$

\section{Consideraciones finales}

La soda solvay se convirtió en un insumo clave del sector industrial, a medida que crecía y se convertía en el motor de la economía las necesidades de producir ese insumo se tornaron cada vez más evidentes.

En los años cuarenta los avances fueron tímidos, el Estado parecía tener interés pero no la convicción de producir localmente soda solvay. Con muchas indefiniciones y en medio de tensiones dejaba en manos de organismos con poca autonomía la realización de frustrados estudios. Por su parte, los empresarios ni siquiera se planteaban la posibilidad de producir soda solvay; quizás los altos costos de la inversión y las características del mercado interno no los estimularon a asumir los riesgos para un proyecto de esa naturaleza.

Luego de veinte años de estudios y frente a los fuertes estrangulamientos externos que sumergían a la economía se tomó la decisión política de producir soda solvay, aún en contra de los diagnósticos, de los importadores y de un contexto inestable que otorgaba incertidumbre al respecto; los empresarios hicieron oídos sordos ante el llamamiento del Estado a participar en su propósito; si bien ahora reconocían su importancia ninguno estaba dispuesto a llevar adelante esa iniciativa.

La orientación económica de los años sesenta afianzó el proceso sustitutivo; los debates intelectuales, el BND y los planes de promoción impulsaban esa estrategia. El Estado había elaborado herramientas que le permitían sumar los capitales privados a su iniciativa.

24 Gral. Albano Harguindeguy, ministro del Interior, a Vicente Naim Pérez, interventor de la CGE de Río Negro, citado en "Soda Solvay: la que está sola y espera", Somos, 19 de agosto de 1977. Landriscina era un cuentista cómico reconocido. 
Álcalis de la Patagonia fue una de las nuevas empresas que se proyectaron en ramas industriales que hasta ese entonces habían quedado rezagadas y en las cuales se ponía el acento por ser generadoras de insumos básicos. En los primeros años setenta, los intentos de construcción de esa planta parecían frustrados, luego los avances muy tímidos durante los gobiernos de facto parecían poner en marcha el proyecto.

La asunción del gobierno peronista modificó la conformación de la empresa. En consonancia con los lineamientos nacionalistas de su política económica, este presionó hacia una mayor participación del capital nacional y parecía darle un nuevo impulso que le permitiría una rápida puesta en funcionamiento. Hasta acá los directivos de la empresa aceptaban las concesiones y las directivas del Estado con bastante quietud; el impulso al proyecto lo daba el Estado.

Sin embargo, con la muerte de Perón, la inestabilidad política profundizada por las diferentes corrientes en el poder que pugnaban por imponer sus distintas concepciones acerca de la política económica provocó indefiniciones respecto a ALPAT e impidió el financiamiento por parte del Estado y por ende cualquier avance en su definición. Luego la crisis económica provocada por el "rodrigazo" pareció echar por tierra todos los intentos por lograr la fabricación local de carbonato de sodio. Sin el auxilio estatal, los empresarios quedaron a la espera de nuevas definiciones al interior del gobierno.

Una vez que se reposicionó en el gobierno la ortodoxia peronista, el proyecto se redefinió; ésta vez el Estado sería el accionista mayoritario pero los alcances de la crisis económica y la posición endeble del gobierno constitucional no permitieron realizar los aportes de capital necesarios para que, de una vez, la planta productora de soda solvay se pusiera en funcionamiento. En principio, los empresarios no se negaron a esa participación estatal mayoritaria y a que dirigiera "su" empresa, al contrario ello le aseguraría un mayor financiamiento por los múltiples canales previstos. El problema suscitó con la crisis política y económica que los relegaba a un segundo plano.

Así, luego de siete años de iniciarse el proyecto para la consecución de un objetivo considerado prioritario, éste quedó enredado en los avatares políticos que le traspasaron sus propias incertidumbres generando una frustración que continuaría en las décadas posteriores. 
La política económica durante la dictadura militar modificó las condiciones en las que operaba la industria hasta el momento y provocó una desindustrialización, pero esta fue "selectiva" y subsistieron algunos grandes proyectos de la etapa anterior. Si bien, podemos observar un retiro del Estado como inversor en ALPAT también destacamos el financiamiento que este le otorga a pesar de que, a diferencia de otros proyectos, en rigor no había comenzado su instalación. En este sentido, resulta indudable que los empresarios presionaban al gobierno para seguir obteniendo financiamiento aunque es más difícil de inferir con qué lo presionaban. Debemos asumir que las vinculaciones de los miembros de ALPAT con algunos funcionarios fueron las que permitieron la continuidad del proyecto.

En un contexto de crecimiento económico con inestabilidad política, el Estado decidió la instalación de una planta para producir soda solvay. De allí en más, la herencia de este proyecto para los sucesivos gobiernos constituyó una pesada carga que no siempre estaban dispuestos a afrontar; sin embargo lo hicieron y en el proceso difícilmente pusieron coto a los empresarios que aprovecharon la incertidumbre reinante para que el Estado financiara por más de treinta años un proyecto de fantasía, pero eso es parte de otro trabajo.

\section{Referencias}

BELINI, Claudio. (2001). DINIE y los límites de la política industrial peronista, 1947-1955. Desarrollo Económico, Buenos Aires, n. 161, abril-junio.

. (2007). La Dirección General de Fabricaciones Militares y su papel en la industrialización de posguerra, 1941-1958. En: Rougier, Marcelo (dir.). Políticas de promoción y estrategias empresariales en la industria argentina. 19501980. Buenos Aires: Ediciones Cooperativas.

PAMPIN, Graciela. (2007). Industria y frustración: el caso de Álcalis de la Patagonia (1940-1976). En: Primeras Jornadas de Historia de la Industria y los Servicios. Facultad de Ciencias Económicas, UBA.

ROUGIER, Marcelo. (2004). Instituciones, finanzas e instituciones en la Argentina. La experiencia del Banco Nacional de Desarrollo 1967-1976. Buenos Aires: UNQ.

. (2007). Una historia poco transparente. El caso de la Fábrica de Vidrios y Opalinas Hurlingham SA. (Inédito).

ROUGIER, Marcelo; FISZBEIN, Martín. (2006). La frustración de un proyecto económico. El gobierno peronista de 1973-1976. Buenos Aires: Manantial. 
SCHVARZER, Jorge. (1978). Estrategia industrial y grandes empresas: el caso argentino. Desarrollo Económico, n. 71, oct-dic.

SCHVARZER, Jorge. (1986). La política económica de Martinez de Hoz. Buenos Aires: Hyspamérica.

. (1996). La industria que supimos conseguir. Buenos Aires: Planeta.

Vaquer, Antonio (1968). Historia de la Ingeniería en la Argentina. Buenos Aires: EUDEBA.

Recebido em 22 de julho de 2008. Aprovado em 2 de setembro de 2008. 